\title{
RESULTADOS E VICISSITUDES DA AVALIAÇÃO DA EDUCAÇÃO SUPERIOR: MECANISMOS IMPLEMENTADOS EM MATO GROSSO DO SUL (1995 A 2002)
}

\author{
SANDra Zákia Lian de Souza* \\ Giselle Martins ReaL
}

\begin{abstract}
RESUMO: O propósito deste texto é evidenciar possíveis impactos que vêm sendo gerados no âmbito das instituições de educação superior, em resposta à sistemática de avaliação implementada pelo governo federal no período de 1995 a 2002. Para tanto, toma-se como referência resultados de pesquisa documental que analisou e cotejou dados estatísticos oficiais, resultados do Exame Nacional de Cursos e pareceres de comissões de avaliação, para fins de autorização e reconhecimento de cursos, focalizando instituições de ensino superior do estado de Mato Grosso do Sul. As evidências coletadas indicam que as modificaçôes ocorridas não se fizeram de modo igual nas instituiçôes públicas e privadas; que o poder indutor da avaliação usualmente leva a uma qualidade formal em detrimento de uma qualidade real e que a sistemática de avaliação, tal como delineada, tende a esgotar seu potencial de estimular alteraçôes nas instituições.
\end{abstract}

Palavras-chave: Política educacional. Avaliação educacional. Educação superior. Regulação e avaliação.

RESULTS AND VICISSITUDES OF THE ASSESSMENT OF HIGHER EDUCATION: IMPLEMENTED MECHANISMS IN MATO Grosso do Sul (1995 to 2002)

ABSTRACT: This paper shows possible impacts on the environment of higher education institutions caused by the systematic assessment implemented by the Brazilian Federal Government

* Doutora em Educação e professora da Faculdade de Educação da Universidade de São Paulo (UsP).E-mail:sanzakia@usp.br

** Doutora em Educação e professora adjunta da Universidade Federal da Grande Dourados (UFGD).E-mail: gcreal@terra.com.br

Educ. Soc., Campinas, vol 30, n. 107, p. 469-488, maio/ago. 2009 
Resultados e vicissitudes da avaliação da educação superior...

from 1995 to 2002. Its reference is the results of a documental research that analyzed and studied the official statistic data from the Exame Nacional de Cursos (National Course Exam) and the points of view of the assessment board that authorizes and recognizes courses. Collected evidences indicate that: the modifications have not taken place homogeneously in public and private institutions; the power guiding assessment usually leads to a formal quality as opposed to real quality, and; this systematic evaluation, as it was designed, tends to empty its potential to motivate changes in these institutions.

Key words: Educational policy. Educational assessment. Higher education.

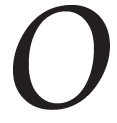

tema da avaliação da educação superior no Brasil, particularmente a partir dos anos de 1990, vem sendo alvo de estudos que, em sua maioria, tendem a explorá-lo em uma perspectiva prescritiva, recomendando fundamentos e metodologias considerados relevantes pelos seus proponentes, ou em uma perspectiva analítica, focalizando a interpretação nos fundamentos e mecanismos das iniciativas que vêm sendo implementados pelo governo federal. Os estudos de natureza prescritiva contemplam proposições a partir de dadas concepções de educação superior e de avaliação, em alguns casos cotejando perspectivas divergentes de avaliação. Quando se trata dos estudos analíticos, a ênfase tende a recair no destaque ao papel controlador do Estado sobre as instituições de ensino superior, pautado pela lógica do mercado, por meio da implementação de princípios e procedimentos voltados ao controle dos produtos educacionais e ao estímulo a competição (Souza \& Oliveira, 2003).

Estes estudos trazem contribuiçôes importantes para o debate. No entanto, há uma carência de investigações que tenham como propósito compreender possíveis impactos que vêm sendo gerados pelas iniciativas governamentais no âmbito das instituições (Franco, 2004; Cury, 2003). Considerando que tais iniciativas se apresentam como propulsoras da qualidade, cabe indagar sobre possíveis impactos na qualidade que possam ser atribuídos à avaliação. Ou seja, investigar o potencial da avaliação, tal como vem sendo conduzida, de induzir a melhoria de qualidade e explicitar que noção de qualidade vem sendo forjada são vertentes ainda pouco exploradas nas investigaçóes. 
É nessa direção que este texto pretende contribuir, tendo como principal referência resultados de pesquisa que teve como um de seus objetivos identificar eventuais impactos dos mecanismos de avaliação implementados no período de 1995 a 2002, em instituições de ensino superior (Real, 2007).

Cabe assinalar que a importância dada, no contexto brasileiro, à avaliação nas políticas de educação superior não se constitui iniciativa isolada, fazendo parte de uma agenda internacional (Leite, 2002). A partir das pioneiras propostas norte-americanas, tem-se, nos anos de 1980, as iniciativas do Reino Unido (Neave, 1988, 1998), estendendo-se gradualmente a quase todos os países europeus, culminando com a proposição de padrōes de qualidade transnacionais em decorrência do Acordo de Bolonha. Na América Latina, acompanhando o movimento internacional, tem-se, especialmente a partir dos anos de 1990, ações desencadeadas em diversos países.

Ao analisar questôes acerca da educação superior na América Latina, Lamarra (2007) assinala que a preocupação com a avaliação na educação superior foi impulsionada, entre outros fatores, pelo grande crescimento do número de instituições e de matrículas no ensino superior, com grande diversificação e simultânea privatização, resultando em níveis muito heterogêneos de qualidade. Nesse contexto é que ganham força as proposiçōes de regulação da qualidade da educação. Também no Brasil, este argumento é recorrente no discurso oficial. Cabe, no entanto, indagar acerca do potencial das açôes implementadas, no sentido de induzir a alteraçōes qualitativas nas instituições de ensino superior (IES) e seus atributos.

O conceito de qualidade não é uma construção simples e vários autores apontam para a complexidade da questão (Diker, 1996; Enguita, 1997). Como segue:

$\mathrm{Na}$ linguagem dos especialistas, das administrações educacionais e dos organismos internacionais, o conceito de qualidade tem invocado sucessivas realidades distintas e cambiantes (...). Hoje em dia, se identifica antes com os resultados obtidos pelos escolares, qualquer que seja a forma de medi-los: taxas de retenção, taxas de promoção, egressos dos cursos superiores, comparaçôes internacionais do rendimento escolar etc. (...). Cada nova versão da qualidade não substitui inteiramente e de uma vez por todas as anteriores: a nova versão afasta as antigas para o lado, mas tem de conviver com elas. (Enguita, 1997, p. 98-99) 
Resultados e vicissitudes da avaliação da educação superior...

Sendo que a avaliação, em essência, supõe a afirmação de valores, na busca pela qualidade, aqui o propósito é explorar quais valores vêm sendo induzidos pelo governo federal e, eventualmente, assimilados pelas IES, por meio das orientações e critérios vigentes no período de 1995 a 2002.

Para explorar tal perspectiva, mesmo que não de modo exaustivo, toma-se como referência alguns dados estatísticos, resultados do Exame Nacional de Cursos e de pareceres de comissões de avaliação, para fins de autorização e reconhecimento de cursos. Para tanto, a análise contemplará dados relativos a IES públicas e privadas do estado de Mato Grosso do Sul.

\section{Destaques do quadro normativo vigente no período 1995 a 2002}

A partir de 1995, as políticas implementadas buscaram efetivar para a educação superior um sistema de avaliação que implicou alterações no processo anterior. ${ }^{1}$ Com a finalidade de verificar o rendimento dos alunos, foi implantado o Exame Nacional de Cursos (ENC). ${ }^{2}$ Também se previu a renovação periódica do reconhecimento dos cursos de ensino superior, conforme disposto na Lei n. 9.131, de 24/11/1995, e demais instrumentos normativos.

A esta Lei, seguiu-se o Decreto n. 2.026, de 14/10/1996, sancionado pela presidência da República, antes mesmo que se realizasse o primeiro ENC, em novembro de $1996 .{ }^{3}$ O referido Decreto prevê que a avaliação de cursos e de instituições de ensino superior contemple as seguintes dimensões:

- Análise dos principais indicadores de desempenho global do sistema nacional de ensino superior, por região e unidade da federação, segundo as áreas do conhecimento e o tipo ou a natureza das instituições de ensino;

- avaliação do desempenho individual das instituições de ensino, compreendendo todas as modalidades de ensino, pesquisa e extensão;

- avaliação do ensino de graduação, por curso, por meio da análise das condições de oferta pelas diferentes instituições de ensino e pela análise dos resultados do Exame Nacional de Cursos;

- avaliação dos programas de mestrado e doutorado, por área do conhecimento. ${ }^{4}$ 
Por força do Decreto n. 3.860, de 09/07/2001, a avaliação das condições de oferta sofreu alterações, inclusive de denominação, passando a ser nomeada de Avaliação das Condições de Ensino. Outros dispositivos foram alterados, dentre os quais a passagem da função avaliadora da Secretaria de Ensino Superior (SESU) para o Instituto Nacional de Estudos e Pesquisas Educacionais (INEP), que passou a ter três linhas de ações: a "avaliação dos principais indicadores de desempenho global do sistema nacional de educação superior" (art. 17, I), a "avaliação institucional do desempenho individual das instituições de ensino superior" (art. 17, II) e a "avaliação dos cursos superiores, mediante a análise dos resultados do Exame Nacional de Cursos e das condições de oferta de cursos superiores" (art. 17, III). Na avaliação institucional foram incluídos, como indicadores, a autoavaliação realizada pela instituição e o Plano de Desenvolvimento Institucional entre os indicadores já anteriormente utilizados. De certa forma, essa inclusão responde às críticas presentes na literatura em relação ao suprimento do PAIUB e à falta de planejamento institucional para a expansão de cursos (Dias Sobrinho, 2003a).

Em uma visão sintética, as principais iniciativas do governo federal voltadas para a avaliação externa dos cursos de graduação foram: a construção de um sistema de informações estatísticas do ensino superior, com a produção dos censos; a verificação do desempenho dos alunos ao final da graduação, por meio do ENC, e o monitoramento das condições de oferta e funcionamento dos cursos e instituições, por meio de autorização e reconhecimento de cursos, credenciamento e recredenciamento institucional.

Diante desse quadro, é possível observar que se confundem as funções de avaliação e de regulação do sistema. $\mathrm{O}$ processo de regulação consiste no controle que o Estado tem sobre as demandas da educação superior, visualizadas, especialmente, nos processos de credenciamento e recredenciamento de instituições e de autorização, reconhecimento e renovação de reconhecimento de cursos, ao passo que o propósito de avaliação seria "a melhoria, não o simples controle" (Dias Sobrinho, 2003b, p. 43).

Como resultante dos mecanismos de avaliação implantados temse a classificação dos alunos em função do desempenho no ENC e das instituiçōes e cursos, em vários graus e categorias distintas (A, B, C, D e E, no caso do "provão", ou CMB, CB, CR e CI, nas avaliações de reconheci- 
Resultados e vicissitudes da avaliação da educação superior...

mento de cursos ${ }^{5}$ ), proporcionadas por critérios específicos, de acordo com a organização administrativa própria à instituição, como instituto superior de educação, faculdade, universidade, centro universitário, entre outras. Dessa forma, a expansão e a diversificação institucional passam a ser regidas pela avaliação (Dourado, Oliveira \& Catani, 2003). A partir de padrôes distintos, forjam-se concepçóes distintas de qualidade, sendo uma para cada forma de organização institucional. Dessa maneira, passou a existir qualidades distintas a partir de critérios diferenciados para universidades, centros universitários, faculdades e institutos superiores de educação.

\section{Quantidade com qualidade?}

O movimento de sistematização da avaliaçãao da educação superior é concomitante com a expansão de instituiçôes, cursos e vagas, que se mostra mais evidente a partir de 1995.

A concepção de qualidade desenhada no período de 1995 a 2002 desassociou quantidade e qualidade, permitindo a expansão de instituições e cursos, notadamente privados, em proporções significativamente maiores do que a realizada nos períodos anteriores (Trindade, 2001; Dias Sobrinho, 2003a).

A política implementada nesse período, diante do objetivo divulgado de induzir quantidade com qualidade, vai construir uma concepção de qualidade diversificada e pautada na relação entre insumos e rendimento. Nesse sentido, são sinalizados novos parâmetros avaliativos na busca por qualidade, considerando a alteração no perfil do ingressante, que passa a ter características de aluno trabalhador e com menor nível socioeconômico (Neave, 1998; Lamarra, 2007). Com isso, nos instrumentos de avaliação governamental, passam a ser considerados como indicadores de qualidade as políticas de bolsas, o apoio psicopedagógico e o nivelamento do discente, junto com indicadores tradicionais como titulação, regime de trabalho do corpo docente e quantidade de acervo bibliográfico.

Os dados da Tabela 1 ilustram a expansão do ensino superior ocorrida no período, evidenciando-se que esta se desenvolveu em duas perspectivas, sendo uma por meio da criação de instituiçóes e de cursos e outra processada pela ampliação do número de vagas e, consequentemente, do número de matrículas. 


\section{Tabela 1}

Expansão de cursos e matrículas do ensino superior no Brasil, considerando os anos de 1995 e 2002

\begin{tabular}{|cccc|}
\hline Ano & Curso & Matrícula & Vaga \\
\hline 1995 & 6.252 & 1.127 .932 & 620.355 \\
\hline 2002 & 14.399 & 3.310 .228 & 1.773 .087 \\
\hline Total (\%) & 130,31 & 193,48 & 185,82 \\
\hline 1995 & 2.782 & 691.490 & 178.145 \\
\hline 2002 & 5.252 & 1.187 .408 & 295.354 \\
\hline Público (\%) & 88,79 & 71,72 & 65,79 \\
\hline 1995 & 3.470 & 1.059 .163 & 432.210 \\
\hline 2002 & 9.147 & 3.621 .759 & 1.477 .733 \\
\hline Privado (\%) & 163,60 & 241,95 & 241,90 \\
\hline
\end{tabular}

Fonte: MEC/INEP; elaboração própria

Como se pode observar, há diferença na dinâmica de expansão entre instituições públicas e privadas. Nas instituições públicas, o maior índice de crescimento se deu por meio da expansão de cursos, ao passo que, nas instituições privadas, o número de matrículas foi o aspecto que apresentou maior crescimento, ou seja, o aumento de matrículas se deu por aumento de vagas e não pela implantação de novos cursos. Enquanto que, em 2002, nas instituiçôes privadas, os cursos apresentaram um crescimento de $163,60 \%$ e as vagas expandiram-se em $241,90 \%$, nas instituições públicas esses percentuais foram respectivamente de $88,79 \%$ e $65,79 \%$.

Correspondendo à expansão de vagas, tem-se uma redução na relação candidato-vaga nos processos seletivos, o que indica menor seletividade no ingresso. Olhando-se no conjunto das instituiçôes privadas, observa-se a tendência para existência de vagas para todos os que as demandam, conforme dados da Tabela 2. Não se pretende, com essa observação, descartar a importância de se ter um maior contingente da população com acesso ao nível superior. $\mathrm{O}$ intuito aqui é 
Resultados e vicissitudes da avaliação da educação superior...

apenas registrar que a maior abertura tende a resultar em maior diferenciação no perfil do ingressante, demandando iniciativas das instituiçôes para lidar com essa diferenciação, de modo que isso não resulte em rebaixamento da qualidade do ensino.

\section{Tabela 2}

Evolução da relação candidatos-vaga nos processos seletivos, por categoria administrativa - Brasil (1993 a 2005)

\begin{tabular}{|cccc|}
\hline ANO & PÚBLICA & PRIVADA & TOTAL \\
\hline 1995 & 7,9 & 2,9 & 4,3 \\
1996 & 7,5 & 2,6 & 4,0 \\
1997 & 7,4 & 2,6 & 3,9 \\
1998 & 7,5 & 2,2 & 3,6 \\
1999 & 8,0 & 2,2 & 3,5 \\
2000 & 8,9 & 1,9 & 3,3 \\
2001 & 8,7 & 1,8 & 3,0 \\
2002 & 8,9 & 1,6 & 2,8 \\
\hline
\end{tabular}

Fonte: $\mathrm{MEC} / \mathrm{INEP}^{6}$; elaboração própria.

Entre as características dos ingressantes que vêm se alterando temse a faixa etária, ou seja, em quatro anos o percentual de alunos com 25 anos ou mais que iniciam um curso superior passou de 36\% para 39\%.

$\mathrm{O}$ fato de estarem chegando aos cursos de graduação alunos mais velhos, possivelmente trabalhadores e, provavelmente, de nível socioeconômico-cultural mais baixo, demandaria, como já se disse, iniciativas de acolhimento institucional que expressassem uma interação com esse alunado que não signifique rebaixamento de expectativas e, por conseguinte, de exigências no padrão de formação. Caberia apreciar a que tipo de instituiçôes e cursos estes alunos vêm tendo acesso. A questão que se coloca é a relação entre democratização do acesso ao ensino superior e seu possível impacto na diminuição de iniquidades sociais. 


\section{Tabela 3}

Distribuição percentual do número de ingressos através de processo seletivo e outras formas, por faixa etária - Brasil (2000-2004)

\begin{tabular}{|ccccc|}
\hline ANO & $\mathbf{1 8}$ a 24 anos & $(\%)$ & 25 anos ou mais & $(\%)$ \\
\hline 2000 & 680.237 & 63,9 & 373.552 & 36,0 \\
2001 & 763.163 & 63,3 & 443.110 & 36,7 \\
2002 & 872.363 & 61,8 & 538.845 & 38,2 \\
2003 & 934.288 & 60,7 & 514.930 & 39,2 \\
2004 & 978.235 & 60,3 & 643.173 & 39,7 \\
\hline
\end{tabular}

Fonte: MEC/INEP; elaboração própria.

É pertinente reproduzir aqui o que expõe Lamarra (2007, p. 54), ao tratar da evolução da educação superior na última década, na América Latina:

$\mathrm{O}$ acesso às instituições de educação superior, públicas e privadas, de melhor qualidade, tem ficado reservado quase que exclusivamente a jovens de classes média e média alta, provenientes de escolas médias, públicas e privadas, de boa qualidade. Os de nível social mais baixo, provenientes de escolas médias públicas de pior qualidade, têm que recorrer a instituições de educação superior, universitárias e não-universitárias, de pior qualidade, em geral privadas, as quais, lamentavelmente, vêm crescendo substantivamente.

Garantir expansão com qualidade é o desafio a ser enfrentado pelas políticas de avaliação do ensino superior. As propostas governamentais do período em análise revelam a crença de que a expansão com qualidade se daria mediante o controle dos resultados da avaliação das instituições de ensino e pela análise dos resultados do ENC, com a advertência de fechamento de cursos que não evidenciassem qualidade. No entanto, não se tem notícia de cursos que tenham sido desativados nesse período (Cunha, 2003).

A seguir, exploram-se evidências de eventuais reflexos que a avaliação vem produzindo nas IES. 
Resultados e vicissitudes da avaliação da educação superior...

Destaques a decorrências da avaliação nas instituições de ensino superior

São diversos os indicadores tomados como referência para avaliação dos cursos e instituições, abrangendo organização didático-pedagógica, insumos, fluxos e processos de trabalho. Nos limites deste artigo, com vistas a explorar a suposição de que a avaliação tenha produzido resultados nos contextos institucionais, tomou-se como referência os indicadores regime de trabalho, titulação do corpo docente e relação professor-doutor por aluno, para o conjunto das instituiçóes abrangidas pelo sistema de avaliação do governo federal. ${ }^{7}$ Optou-se por considerar esses indicadores por compor o conjunto dos levantamentos considerados pelo INEP, ao produzir os censos da educação superior. Cumpre destacar que os censos são tomados como instrumento para a avaliação dos indicadores de desempenho global, previsto nos decretos n. 2.026/1996 e n. 3.860/2001.

Também foram tomados como base para a investigação os demais instrumentos de avaliação considerados pelos dois decretos mencionados, ou seja, os resultados do ENC e os relatórios das comissōes de especialistas no momento das visitas in loco, conforme já mencionado. Para este trabalho, foram referenciadas as instituições de Mato Grosso do Sul, como uma forma de dimensionar o volume dos documentos a serem analisados.

Quanto ao regime de trabalho em tempo integral, a concentração desta modalidade de contratação se dá nas universidades públicas, correspondendo a $92,22 \%$ dos docentes nessa condição contratual, conforme Tabela 4. Os dados referentes às universidades privadas revelam um pequeno crescimento do percentual de docentes em regime de tempo integral, comparando-se os anos de 1995 e 2002, passando de $20,35 \%$ para $20,76 \%$, perfazendo um aumento de 0,41 pontos percentuais.

Em relação à titulação, no entanto, pode-se afirmar que houve ampliação na presença de professores com esta característica, conforme pode ser visto na Tabela 5.

Mesmo considerando a expansão ocorrida no período, nota-se que houve redução do número de alunos por professor-doutor no decorrer dos anos de 1995 a 2002, tanto nas instituições públicas quanto nas privadas, conforme dados da Tabela 6 . 


\section{Tabela 4}

Regime de trabalho dos docentes de IES, públicas e privadas - Brasil (1995 e 2002)

\begin{tabular}{|c|c|c|c|c|c|c|}
\hline & \multicolumn{2}{|c|}{ UNIVERSIDADE } & \multicolumn{2}{|c|}{$\begin{array}{c}\text { CENTRO } \\
\text { UNIVERSITÁRIO }\end{array}$} & \multicolumn{2}{|c|}{ FACULDADE } \\
\hline & No & $\%$ & No & $\%$ & No & $\%$ \\
\hline 1995 & 57.774 & 57,13 & - & - & 5.751 & 13,02 \\
\hline 2002 & 80.353 & 52,52 & 4.230 & 17,68 & 9.881 & 15,07 \\
\hline $\begin{array}{c}\text { TOTAL } \\
\text { Brasil }(\%)\end{array}$ & 39,08 & $-4,61$ & - & - & 71,81 & 2,05 \\
\hline 1995 & 50.909 & 75,53 & - & - & 3.133 & 35,36 \\
\hline 2002 & 65.808 & 79,36 & 191 & 31,26 & 4.005 & 46,16 \\
\hline $\begin{array}{l}\text { TOTAL } \\
\text { Público }\end{array}$ & 29,27 & 3,83 & - & - & 27,83 & 10,8 \\
\hline 1995 & 6.865 & 20,35 & - & - & 2.618 & 7,42 \\
\hline 2002 & 14.545 & 20,76 & 4.039 & 17,32 & 5.876 & 10,33 \\
\hline $\begin{array}{c}\text { TOTAL } \\
\text { Privadas }\end{array}$ & 11,87 & 0,41 & - & - & 124,45 & 2,91 \\
\hline
\end{tabular}

Fonte: MEC/INEP; elaboração própria.

\section{Tabela 5}

Percentual de mestres e doutores, ${ }^{8}$ por categoria administrativa, considerando as funções docentes - Brasil (1995 e 2002)

\begin{tabular}{|c|c|c|c|c|c|c|c|c|}
\hline \multirow{3}{*}{ Brasil } & \multicolumn{4}{|c|}{ Universidade } & \multicolumn{4}{|c|}{ Faculdade } \\
\hline & \multicolumn{2}{|c|}{ Pública } & \multicolumn{2}{|c|}{ Privada } & \multicolumn{2}{|c|}{ Pública } & \multicolumn{2}{|c|}{ Privada } \\
\hline & M & D & $\mathbf{M}$ & D & M & D & M & D \\
\hline 1995 & 30,09 & 25,73 & 22,11 & 9,41 & 17,19 & 6,76 & 15,91 & 4,80 \\
\hline 2002 & 30,39 & 38,48 & 38,02 & 14,82 & 29.55 & 13,79 & 36,89 & 8.29 \\
\hline
\end{tabular}

Fonte: MEC/INEP; elaboração própria.

Educ. Soc., Campinas, vol 30, n. 107, p. 469-488, maio/ago. 2009 


\section{Tabela 6}

Evolução da relação aluno matriculado por professor-doutor no Brasil, por tipo de instituição, nos anos de 1995 a 2002

\begin{tabular}{|ccc|}
\hline Ano & $\begin{array}{c}\text { Relação professor-doutor em } \\
\text { instituiçóes privadas }\end{array}$ & $\begin{array}{c}\text { Relação professor-doutor em } \\
\text { instituiçōes públicas }\end{array}$ \\
\hline 1995 & 193,3 & 37,8 \\
1996 & 174,9 & 35,7 \\
1997 & 157,6 & 32,2 \\
1998 & 138,0 & 31,7 \\
1999 & 124,0 & 29,4 \\
2000 & 118,3 & 28,7 \\
2001 & 119,1 & 28,3 \\
2002 & 121,8 & 29,0 \\
\hline
\end{tabular}

Fonte: MEC/INEP; elaboração própria.

As informações constantes nas tabelas 4 e 5 evidenciam que houve avanço no número de professores titulados, inclusive no número de doutores, tanto nas instituiçōes privadas quanto nas públicas. Sinalizase que o avanço nas instituições privadas foi maior do que nas públicas, uma vez que o crescimento nas instituiçóes privadas, considerando os anos de 1995 e 2002, foi na ordem de 39,1\% e nas públicas foi na ordem de 23,3\%. No entanto, esse crescimento ainda não foi capaz de alterar o cenário que aponta a existência de um perfil de corpo docente com maior formação nas instituições públicas, evidenciado na diferença significativa entre a relação de aproximadamente 122 alunos por professor-doutor presentes nas instituições privadas e de 29 alunos por professor-doutor nas públicas.

Como em âmbito nacional os dados a que se tem acesso são escassos, não possibilitando a análise mais abrangente de eventuais impactos que as iniciativas de avaliação engendraram nas IES, a pesquisa (Real, 2007) aprofundou os levantamentos em instituições e cursos do estado de Mato Grosso do Sul, evidenciando movimentos ocorridos nesse contexto, tomando como referência os resultados do ENC e pareceres das comissões de avaliação, para fins de autorização e reconhecimento de cursos. Embora os achados não possam ser extrapolados para o âmbito nacional, ilustram como instituições e cursos interagiram com 
a avaliação. Seguem-se alguns destaques feitos pela autora na conclusão de sua investigação.

Ao analisar os relatórios das comissões de avaliação in loco, constatou-se a tendência das instituições em acatar os padrôes de qualidade relativos a organização didático-pedagógica, ao corpo docente e as instalaçôes, tal como definidos pelas comissões de especialistas, responsáveis pela avaliação.

As alterações institucionais mais claramente identificas nas instituições referem-se ao maior número de professores titulados e contratados em regime de tempo integral; currículos construídos de acordo com diretrizes curriculares nacionais; informatização; ampliação do acervo bibliográfico; implantação de laboratórios e adequação de instalaçôes a deficientes. No entanto, tais resultados foram identificados em intensidade diferente nas instituiçôes públicas e privadas, sendo mais evidentes nestas últimas. Os pareceres acerca de instituições públicas, ao contrário, revelavam precariedade em suas condições de funcionamento, particularmente em suas instalações.

No entanto, os alunos oriundos de universidades públicas foram os que, em geral, apresentaram melhor desempenho no ENC, o que indica que as alterações implantadas nas IES privadas não se refletiram, ao menos no período estudado, no desempenho dos alunos nos exames. Tal constatação pode ser explicada, em parte, por diferenças no nível socioeconômico dos ingressantes em instituiçõoes públicas e privadas. ${ }^{9}$ Contudo, além disso, há indicações na pesquisa de Real (2007) que alertam para o fato de que a dinâmica e relaçôes de trabalho, nas instituições privadas, parecem ter sido pouco alteradas, apesar dos aportes implantados para o desenvolvimento do trabalho.

Tendo em conta pareceres dos membros de comissões de avaliação, foi possível identificar, por exemplo: precariedade de atividades de pesquisa e extensão, tanto do corpo docente como discente; baixa produção científica, embora haja maior número de professores mestres e doutores; professores contratados em tempo integral, com quase toda a sua carga horária dedicada a ministrar aulas; número elevado de alunos por sala, quando comparado com as instituições públicas; número de funcionários técnico-administrativos não acompanha a ampliação de cursos e vagas.

Cumpre destacar que os membros das comissōes de avaliação, que produziram os pareceres aqui considerados, são professores universitários 
Resultados e vicissitudes da avaliação da educação superior...

designados pela SESU no período de 1996 a 2001 e pelo INEP a partir de 2002. No período de 1997 a 2001, houve três nomeações de comissões de especialistas (Portarias SESU/MEC n. 972/1997, n. 146/1998 e n. $1.518 / 2000)$, havendo modificações em grade parte de seus membros, mas permanecendo o seu perfil, no qual quase a totalidade era composta por professores vinculados à universidades públicas. As avaliaçôes eram desencadeadas a partir de formulários de avaliação criados por áreas dos cursos, especificamente para esse processo, identificados como "padrōes de qualidade". Os "padrões de qualidade" foram elaborados a partir dos indicadores de qualidade presentes no Decreto n. 2.026/1996 e na Resolução n. 641/1997, que, em linhas gerais, consideravam a organização didático-pedagógica, o corpo docente, a biblioteca e a infraestrutura física das instituiçôes.

Há evidências, nos pareceres dos avaliadores, de iniciativas institucionais que são desencadeadas às vésperas da visita da comissão de avaliação, em função de demonstrar atendimento aos critérios de avaliação. A título de exemplo, pode-se mencionar trecho de um parecer de reconhecimento de curso que, sobre a biblioteca, registrava:

“(...) O acervo apresenta-se conforme o desenvolvimento do Curso a partir do presente momento. O que se sugere aqui é que, pela análise dos exemplares e das fichas de aquisição, percebe-se um movimento de compra bastante intenso nas últimas semanas; o mesmo não pôde ser visto em relação a períodos anteriores".

Em outro parecer há a seguinte inscrição: “(...) Os professores contratados em regime de tempo integral possuem mais de 30 horas de efetiva docência, o que os torna professores horistas, com grande carga horária dedicada ao ensino”.

As decorrências da avaliação nas instituições de ensino superior aqui destacadas sugerem que as IES privadas mobilizaram-se para atender aos critérios estabelecidos nas normas e orientaçōes emanadas do governo federal, visando a obtenção de conceitos positivos. No entanto, parecem pouco alterar a lógica de sua organização e dinâmica de trabalho. Observa-se que essas instituições mantiveram sua gestão com base na relação custo-benefício. No caso de instituições públicas, o movimento ocorrido em resposta aos mecanismos de avaliação parece ter sido menos intenso. Por um lado, já contavam com algumas das condiçóes exigidas, 
particularmente no que se refere à titulação e regime de trabalho do corpo docente e o envolvimento com atividades de pesquisa e extensão, além de seus alunos, em geral, obterem bons resultados no ENC. Por outro, evidenciaram uma precarização em suas instalações, cujos resultados das avaliações não tiveram força para impulsionar melhorias.

\section{Indicações finais}

É possível inferir que a avaliação processada no período de 19952002 induziu as instituições e cursos a um movimento de buscar atender aos critérios estabelecidos, até mesmo por ser essa uma condição para obtenção de seu credenciamento. Como já se observou, os eventuais impactos não se fizeram de modo igual nas instituições públicas e privadas, até mesmo porque a concepção de qualidade que inspira os critérios de avaliação expressa a concepção dominante nas universidades públicas, particularmente em termos de titulação e regime de trabalho do corpo docente, existência de planos de carreira e salários, produção acadêmica e desenvolvimento de atividades de pesquisa e extensão, para além do ensino, no caso de universidades.

Contudo, pode-se inferir que os avanços ficaram condicionados ao cumprimento da legislação, sobretudo na consideração das diretrizes curriculares nacionais nas propostas de ensino, ao número mínimo de professores com mestrado e doutorado e à contratação de professores com regime de tempo integral, entre outros aspectos que passam a ser monitorados, de forma frequente, pelo processo de avaliação. Com isso, verifica-se a correlação existente entre regulação e avaliação.

Ao mesmo tempo em que as universidades privadas passaram a atender aos indicadores de qualidade, estabelecidos a partir do ideal de qualidade das universidades públicas, estas foram vivenciando um processo inverso que, por meio da escassez de recursos, implicou a não atualização das instalações físicas e condições para o trabalho acadêmico, agravada pela aposentadoria precoce de professores, o que se traduziu na contratação de professores temporários, muitas vezes menos qualificados, processo registrado em relatórios elaborados por comissóes de especialistas.

A avaliação pode ser conduzida como meio para o estabelecimento de uma política de ensino superior, de acompanhamento de sua 
Resultados e vicissitudes da avaliação da educação superior...

implementação e, ainda, como via para possibilitar a transparência de resultados das IES. Ao que parece, no entanto, assiste-se a uma inversão, qual seja, a avaliação vem ganhando mais visibilidade do que o debate e delineamento da própria política de educação superior (Sousa, 2001).

Tal inversão pode explicar em parte uma das inferências oriundas da pesquisa de Real (2007), qual seja, a de que a busca das instituições pela obtenção de conceitos positivos nas avaliaçôes que atestem a boa qualidade de seus serviços vem proporcionando uma qualidade formal, em detrimento de uma qualidade real. A expressão qualidade real, aqui empregada, procura explicitar que a qualidade não pode estar relacionada apenas pelos seus aspectos extrínsecos, relativos ao contexto político e cultural, mas deve considerar, também, os aspectos intrínsecos, relacionados com os objetivos e a ação pedagógica de cada instituição (Sander, 1995). É possível supor que pouco impacto venha ocorrendo nos propósitos institucionais; alteram-se alguns procedimentos e condições de trabalho, o que pode ser algo com potencial de provocar melhoria do ensino, mas não se transformam substantivamente os seus propósitos. Lembra-se que a avaliação

(...) não é algo que se dê de modo dissociado do objeto ao qual se dirige e não se concretiza independentemente dos valores dos sujeitos em interação. Assim, os princípios norteadores de uma proposta avaliativa e de seu próprio processo de construção representam uma explicitação do posicionamento dos sujeitos frente a um determinado segmento da realidade, sujeitos esses que ocupam diferentes lugares sociais, o que leva ao afloramento de divergentes e conflitantes ênfases na avaliação. (Amorim \& Sousa, 1994, p. 125)

Portanto, a tentativa de induzir a uma dada qualidade das instituições, por meio da avaliação, tem seus limites.

É possível conjeturar que as alterações ocorridas nas instituições, em decorrência da avaliação, estão chegando a um limite, ou seja, seu potencial indutor de rumos parece que pouco pode avançar para além do tipo e natureza de alteraçôes como as que se constatou com a pesquisa. Estas tendem a se traduzir em maior número de professores titulados, em melhores instalaçôes e maior número de professores em regime de tempo integral, mesmo que ocupando quase todo este tempo com carga didática. 
Fica o desafio de se buscar avançar na construção de um processo avaliativo que, não se confundindo com regulação, tenha como perspectiva avançar para além de critérios formais, incorporando critérios que remetam a reflexão sobre qual tem sido o compromisso políticopedagógico das instituições, no sentido de possibilitar uma articulação entre a formação, o conhecimento produzido e os reais problemas da sociedade brasileira.

Ao que parece, o desafio em garantir acesso com qualidade ainda não foi atingido.

\section{Recebido em junho de 2008 e aprovado em agosto de 2008.}

\section{Notas}

1. Até a entrada em vigor da Lei n. 9.131/1995, o processo de avaliação da educação superior era desenvolvido pelo Conselho Federal de Educação, que era processado por meio de comissão de especialistas por área de conhecimento, com vistas à avaliação in loco dos cursos a serem autorizados e reconhecidos. Nesse período, não havia processos periódicos de avaliação e, portanto, não existiam os processos de renovação do reconhecimento dos cursos, nem mesmo recredenciamento de instituições.

2. No caso do ensino de graduação, antecedendo o ENC, foram implementados no Brasil: o PARU - Programa de Avaliação da Reforma Universitária (1983), o GERES - Grupo Executivo para a Reformulação do Ensino Superior (1986) e o PAIUb - Programa de Avaliação Institucional das Universidades Brasileiras (1993).

3. Em 1996, foram examinados os alunos concluintes dos cursos de Direito, Administração e Engenharia Civil; em 1997, foram também examinados os concluintes dos cursos de Engenharia Química, Veterinária e Odontologia. Pela proposta, a cada ano, novos cursos eram incorporados.

4. O presente texto focaliza o ensino de graduação, daí não abranger consideraçôes acerca da avaliação dos programas de mestrado e doutorado, desenvolvida pela Fundação Coordenação de Aperfeiçoamento de Nível Superior (CAPES) desde 1976.

5. Os conceitos utilizados pelo ENC, representados pelas letras maiúsculas A, B, C, D e E, tipificam os resultados obtidos pela média dos alunos, de forma que A corresponde ao melhor desempenho apresentado pelo aluno e $\mathrm{E}$ ao pior. A avaliaçáo das condiçốes de ensino utiliza-se dos conceitos CMB para as instituições que apresentarem Condiçôes Muito Boas, Св para as Condiçōes Boas, CR para as Condiçōes Regulares e CI para as Condições Insuficientes. Cumpre destacar que as instituiçōes que obtinham CR e CI passavam por processo de diligência, no sentido de sanear os problemas detectados.

6. Não há dados sobre a faixa etária dos ingressos, anteriores ao ano 2000, ano em que o INEP incluiu esse quesito no Censo da Educação Superior (conforme resposta obtida de Laura Bernardes da Silva, Coordenadora do Censo, fornecida por e-mail, datado de 12 de maio de 2006).

Educ. Soc., Campinas, vol 30, n. 107, p. 469-488, maio/ago. 2009

Disponível em <http://www.cedes.unicamp.br> 
Resultados e vicissitudes da avaliação da educação superior...

7. As universidades estaduais não fazem parte do sistema federal de ensino, podendo ter processo de avaliação próprio estabelecido pelos sistemas estaduais, por força do processo de descentralização/desconcentração, presente nos dispositivos jurídico-legais brasileiros. Assim, não fazem parte do objeto deste trabalho.

8. Para a organização dos dados na categoria doutores, somaram-se informaçôes referentes a professores doutores, pós-doutores e livre-docentes.

9. Observa-se que, com a adoção do Exame Nacional de Desempenho de Estudantes (ENADE), a partir de 2004, as políticas de avaliação buscam identificar o valor que o curso/instituição vem agregando ao aluno, considerando inclusive o seu perfil socioeconômico (Pacheco $\&$ Ristoff, 2005).

\section{Referências}

AMORIM, A.; SOUSA, S.M.Z.L. Avaliação institucional da universidade brasileira: questões polarizadoras. Estudos em Avaliação Educacional, São Paulo, n. 10, p. 123-136, jul./dez. 1994.

BRASIL. Lei n. 9.131, de 24 de novembro de 1995. Altera dispositivos da Lei n. 4.024, de 20 de dezembro de 1961 e dá outras providências. In: LEGISLAÇÃO e normas de pós-graduação brasileira. Brasília, DF: FUNADESP, 2001.

BRASIL. Ministério da Educação. Decreto n. 2.026, de 10 de outubro de 1996. Estabelece procedimentos para o processo de avaliação dos cursos e instituições de ensino superior. Disponível em: <http:// www.mec.gov.br/Sesu/ftp?Decreto2026.doc> Acesso em: 5 jul. 2003.

BRASIL. Ministério da Educação. Decreto n. 3.860, de 9 de julho de 2001. Dispõe sobre a organização do ensino superior, a avaliação de cursos e instituições, e dá outras providências. Disponível em: <http://mec.gov.br/sesu.ftp/decreto/decN3860.doc> Acesso em: 5 jul. 2003.

CUNHA, L.A. O ensino superior no octênio FHC. Educação \& Sociedade, Campinas, v. 24, n. 82, p. 37-61, abr. 2003.

CURY, C.R.J. A educação superior: setor público e iniciativa privada. In: Morhy, L. (Org.). Universidade em questão. Brasília, DF: UnB, 2003. p. 473-486.

DIAS SOBRINHO, J. Avaliação: políticas educacionais e reformas da educação superior. São Paulo: Cortez, 2003a. 
DIAS SOBRINHO, J. Avaliação da educação superior, regulação e emancipação. In: Dias Sobrinho, J.; Ristoff, D.I. (Org.). Avaliação e compromisso político: a educação superior em debate. Florianópolis: Insular, 2003b. p. 35-52.

DIKER, G. La evaluación de la calidad como dispositivo de regulación social. In: REUNIĀO ANUAL DA ANPED, 19, 1996, Caxambú. (mimeo.).

DOURADO, L.F.; OLIVEIRA, J.F.; CATANI, A.M. Transformações recentes e debates atuais no campo da educação superior no Brasil. In: Dourado, L.F.; Oliveira, J.F.; Catani, A.M. Políticas e gestão da educação superior. São Paulo: Xamã, 2003. p. 17-30.

FRANCO, C. Quais as contribuições da avaliação para as políticas educacionais? In: Bonamino, A.; Bessa, N.; Franco, C. (Org.). Avaliação da educação básica. Rio de Janeiro: Loyola, 2004. p. 45-63.

LAMARRA, N.F. Hacía uma nueva agenda de la educación superior en América Latina, algunos desafios políticos, sociales e académicos. Avaliação, Campinas, v. 12, n. 1, p. 45-72, mar. 2007.

LEITE, D. Avaliação institucional, reformas e redesenho capitalista das universidades. Avaliação, Campinas, v. 7, n. 2, p. 29-48, jun. 2002.

NEAVE, G. On the cultivation of quality, efficiency and enterprise: an overview of recent trends in higher education in Western Europe, 1986-1988. European Journal of Education, Paris, v. 23, n. 1/2, p. 723, 1988.

NEAVE, G. The evaluative State reconsidered. European Journal of Education, Paris, v. 33, n. 3, 1998.

PACHECO, E.; RISTOFF, D. Construindo o futuro. In: Genro, T. et al. Seminário Internacional "Reforma e avaliação da educação superior": tendências na Europa e na América Latina. São Paulo; Brasília, DF: INEP, 2005. p. 45-51.

REAL, G.C.M. A qualidade revelada na educação superior: impactos da política de avaliação no Brasil. 2007. Tese (Doutorado em Educação) - Faculdade de Educação, Universidade de São Paulo, São Paulo. 
Resultados e vicissitudes da avaliação da educação superior...

SANDER, B. Gestão da educação na América Latina: construção e reconstrução do conhecimento. Campinas: Autores Associados, 1995.

SOUSA, S.M.Z.L. Avaliação e políticas educacionais: iniciativas em curso no Brasil. In: Hidalgo, A.M.; Silva, I.F. (Org.). Educação e Estado: as mudanças nos sistemas de ensino no Brasil e Paraná na década de 90. Londrina: UEL, 2001. p. 69-98.

SOUSA, S.M.Z.L.; OLIVEIRA, R.P. Políticas de avaliação da educação e quase mercado no Brasil. Educação \& Sociedade, Campinas, v. 24, n. 84, p. 873-895, set. 2003.

TRINDADE, H. As metáforas da crise: da "universidade em ruínas" às "universidades na penumbra” na América Latina. In: Gentili, P. (Org.). Universidades na penumbra. São Paulo: Cortez, 2001. p. 13-43. 